\title{
From Prototype to Deployable System: Framing the Adoption of Digital Library Services
}

\section{Leonard W. D'Avolio, Corresponding Author}

Department of Information Studies University of Califomia, Los Angeles. Los Angeles, CA 90095-1520. Idavolio@ucla.edu

\section{Christine L. Borgman}

Department of Information Studies University of Califomia, Los Angeles. LoS Angeles, CA 90095-1520. borgman@gseis.ucla.edu

\section{Leslie Champeny}

Department of Information Studies University of Califomia, Los Angeles. Los Angeles, CA 90095-1520. Ichampeny@ucla.edu

\section{Gregory H. Leazer}

Department of Information Studies University of Califomia, Los Angeles. Los Angeles, CA 90095-1520. gleazer@ucla.edu

\section{Anne J. Gilliland}

Department of Information Studies University of Califormia, Los Angeles. LoS Angeles, CA 90095-1520. swetland@ucla.edu

\section{Kelli A. Millwood}

Dept. of Education University of California, Los Angeles. Los Angeles, CA 90095-1520. millwood@ucla.edu

The Alexandria Digital Earth Prototype Project (ADEPT) is a 5-year (1999-2004) effort, with a goal of developing effective models for implementing digital 
libraries in undergraduate instruction. The ADEPT team has created a digital learning environment (DLE) that adds educational value to a digital library by offering a suite of services for teaching. Encouraged by the results of implementations in undergraduate geography classrooms, the team now shifts its focus from experimental prototype to deployable system. Everett Rogers' Diffusion of Innovations theories are used as frameworks for analyzing this complex transition. Recommendations for lowering the barriers to adoption related to complexity, trialability, and observability include the prioritization of development efforts focused on stabilizing the system, the creation of documentation and an online demonstration, and anonymous logins to the system. To increase perceived relative advantage, existing technical and copyright issues in integrating the Alexandria Digital Library must be overcome. To increase compatibility, the speed at which pedagogical change is achieved must be rethought. Finally, recruitment efforts should focus on innovators and early adopters before moving on to early majority, late majority, or laggard adopters.

Introduction

As part of the National Science Foundation's Digital Libraries Initiative Phase 2 (http:/ / dli2.nsf.gov), the Alexandria Digital Earth Prototype Project (ADEPT) (http:/ / www.alexandria.ucsb.edu) is a 5-year (1999-2004) effort, with a goal of developing effective models for implementing digital libraries in undergraduate instruction. More specifically, the ADEPT team has created a digital learning environment (DLE) that adds educational value to a digital library by offering a suite of senvices for teaching. The education and evaluation components of the project, led by the University of California, Los Angeles (UCLA) (http:/ / is.gseis.ucla.edu/ adept) have attempted to answer the following question: how does one design technology capable of facilitating a pedagogical change in instructors' approaches to classroom learning. More specifically, how can technology drive a curriculum based on hypothesis formulation rather than rote memorization to foster "active learning" (Dewald and Clair, 1997; Modell and Michael, 1993)? Efforts to answer this question have resulted in 
research by the evaluation and education team on geographic education, digital library design, and the practices and goals of faculty, teaching assistants, and students (Borgman, Gilliland-Swetland, Leazer, Mayer, Gwynn, Gazan and Mautone, 2000; Borgman, Leazer, Gilliland-Swetland and Gazan, 2001; Gazan, Leazer, Borgman, Gilliland-Swetland, Smart and al., 2003; Gilliland-Swetland and Leazer, 2001; Leazer, Gilliland-Swetland, Borgman and Mayer, 2000; Mayer, Mautone and Prothero, 2002).The conceptual and technical design and development of the ADEPT system has been led by the University of California, Santa Barbara (http:// wuw.alexandria.ucsb.edu/ research/index/ htm) (Hill and Freeston, 2003; Hill, Carver, Larsgaard, Dolin, Smith, Frew and Rae, 2000; Janee, 2003; J anee and Frew, 2002).

An iterative approach to the development and refinement of the DLE has yielded postclass evaluations that indicate usability and functionality improvements for the participating instructors (Champeny, Borgman, Leazer, Gilliland-Swetland, Millwood, D'Avolio, Finley and Smart, 2004). Most recently, the evaluation of the spring 2003 implementation of the ADEPT DLE showed student's learning outcomes significantly improved in scientific reasoning ability when compared to fall 2002 results, specifically on tests of graph comprehension and hypothesis generation (Champeny, Borgman et al., 2004). Furthermore, participating students found classroom presentations with the DLE to be useful for understanding concepts.

However, each of the studied implementations has relied heavily on the efforts of ADEPT team members, whose intense involvement has been required in the development of classroom materials and use of the system. Encouraged by the potential of the system to contribute to classroom learning, the ADEPT team now shifts its focus from the development of an experimental prototype to a widely deployable system for classroom use. This review explores the myriad of challenges that will need to be addressed through the lens of Rogers' Diffusion of Innovation (DOI) theories, in order to complete this complex transition.

\section{Background}




\section{The ADEPT DLE}

The ADEPT Digital Learning Environment (DLE) is a suite of tools designed to encourage the use of digital libraries in classroom learning. While the specific functionalities of the DLE have evolved throughout the system's creation (Champeny, Borgman et al., 2004), the basic premise behind its design in 2001 was "concept-based learning." As described by the development team in meetings and interviews, concept-based learming descends from a vision of scientific knowledge as "strongly structured" concepts, and of scientific activity as the discovery and formal modeling of individual concepts, including their relationships to each other in larger knowledge domains (see (Smith and Zeng, 2002) for a discussion of science as strongly structured concepts). The ADEPT system was designed to build such domains of conceptual knowledge as computerized "concept knowledge bases" in digital library collections, and even as forming a potential basis for eventual integration into an emergent artificial intelligence. At the same time, concept-based leaming descends from a vision of education as "active learning" (Dewald and Clair, 1997; Modell and Michael, 1993), and of science education as teaching students how to discover and model scientific concepts. The ADEPT system was originally envisioned to enable access to primary data sources and enhance their use in hypothesis generation and testing, even becoming a distributed, dynamic, interactive digital text.

As a result, users of the ADEPT DLE can create geographic "concepts" through the system's Lecture Composer. Examples of typical geographic concepts include erosion or river delta. Relationships between the concepts can be defined through the "Concept Grapher" which can then be used to help convey the interrelatedness of the topics being presented in a class. For example, a relationship can be drawn between river delta and erosion, illustrating the connectedness between the two concepts. The system is Webbased, and can be accessed online by both professors and students through a single interface. During in-class presentations, lectures can be displayed on up to three presentation screens simultaneously, depending on the set up of the physical classroom, allowing instructors to present lecture content, complementary multimedia, and a concept map. The resulting "teaching objects" can then be stored to a server, allowing other instructors to use existing materials in their lectures. 


\section{The Design Process}

From an educational perspective, the ADEPT project's intent is to utilize technology to drive pedagogical change. Rather than move traditional learning methods from the blackboard to the projector, the ADEPT team's goal is to develop new approaches to teaching geographic content. The ADEPT evaluation team has recognized that the creation of a system capable of meeting our ultimate design goal of improving classroom leaming will only be valuable if it is easy enough to use and it provides sufficient value that faculty will choose to use it for their teaching (Borgman, Smart, Millwood, Finley, Champeny, Gilliland-Swetland and Leazer, 2004). This understanding led to the development of general design principles which state that ADEPT should be easy to leam and use by instructors, improve teaching productivity, and create minimal additional workload for instructors (Gilliland-Swetland and Leazer, 2001).

The developers from the UCSB team also committed to technical design principles to guide their development efforts. These include flexibility, openness, and ease of use. They wanted their system to be cross-platform and browser compatible and capable of either incorporating existing course materials or building them from scratch with "pushbutton publishing." They were committed to open source and "openly accessible" Webbased design and envisioned a community of users capable of easily sharing collections of research and course materials in digital libraries. In contrast to existing geographic information systems, which are highly specialized and feature steep learning curves, the design team's goal was to create a widely useful and intuitive system.

Without existing blueprints, the ADEPT team took an approach of iterative, formative evaluation; a process in which system design is studied in parallel with user needs and requirements (Borgman, Leazer et al., 2001). The ADEPT team's management encouraged divergent views for both the technological choices and the proposed functionalities of the DLE. In order to facilitate this, the team's four developers worked independently, selecting the technologies that they deemed to be appropriate for their portions of the application. Concurrent development of various components allowed the team to explore best possible approaches to the development of such a system. It also 
led to challenges to integrating the various components of the system, as the cataloging component for describing newly entered content was developed with PHP, the main interface to the application was created in Flash, and the Lecture Composer was XML driven. Concurrent development of various components of the system also resulted in technical difficulties in integrating the ADEPT DLE with the Alexandria Digital Library. At the time of this writing, the ability to automatically import images from the $A D L$ is reportedly close to completion.

Hypotheses on the best way to inspire pedagogical change in the early stages of the system's creation were tested through system design and review, mostly by the combined ADEPT team. This group featured active professors, including an undergraduate geography professor who served as a leading designer of the system. As the system progressed, the testing grounds for conceptual development became the undergraduate geography classroom. Professors were recruited from two universities, as well as teaching assistants, who were willing to experiment with the technology. Their agreement to participate was in some cases tentative and in others enthusiastic. In all instances, the decision to participate was complemented by the support of ADEPT staff throughout the process. This approach not only offered participating instructors the technical support needed, but also allowed the ADEPT design team to gather valuable insights and feedback, which drove design and development efforts. As a result of this iterative and flexible approach to development, the functionalities of the ADEPT DLE have evolved dramatically, and have included entire redesigns of the DLE on more than one occasion based on classroom implementation experiences (Champeny, Borgman et al., 2004).

With the intent of creating a model for effective and innovative uses of digital libraries in the classroom, the ADEPT team views evaluation not as a judgment of success or failure, but rather as a clarification of the underlying theory, design plausibility and implementation consistency of a program or project (Owen, Calnin and Lambert, 2002). The focus of our research thus far has been the design of a demonstration prototype, rather than a finished, marketable product. As such, our prototype testing has been conducted iteratively in complex and changing environments with direct developer involvement throughout. 
Investing effort in developing a more stable system during the experimental deployments of the system would have limited the flexibility of the system and distracted the design team from further developing the experimental functionalities necessary to test their design hypotheses. Instead, the method of tipping the scale in favor of instructor participation for our classroom implementations thus far has been to subsidize the amount of effort related to the conversion of an instructor's lecture from its existing format into the Lecture Composer. The ADEPT team has also assumed any perceived costs resulting from technical support. In order to deliver these benefits to the instructor, ADEPT team members have guided all training efforts and technical support and have maintained a presence in most classes using the DLE. To further support instructors, graduate geography students have been assigned to contribute to the creation of content for most courses using the Lecture Composer.

As the team transitions from experimental prototype to deployable system, the formula used to tip the adoption decision in our favor must now change dramatically. The removal of the robust support system previously offered to instructors takes with it the comfort of an always-available staff to solve technical problems and the attractive convenience of ready-made lectures and multimedia material delivered to instructors for their classes. As new barriers to adoption are introduced into the equation, it becomes necessary to devise a strategy to recalibrate the adoption equation in ADEPTs favor if the project is to transition from providing answers to research questions to becoming a sustainable system for changing the pedagogy of geography instruction and promoting the classroom use of digital libraries.

\section{Literature Review}

The potential of computerized information technologies to improve learning has long been assumed but less often confirmed. Evaluators of educational technology curricula note that the process of designing and implementing such programs is complex, and requires both technological and pedagogical expertise. The experiences of the ADEPT research and development teams confirm the complexities of this process. Building and using a digital library environment to its greatest potential requires the design of both 
new information management technologies and new senvices for collection creation and development, resource description and discovery, and information use. Evaluating the design and implementation of the ADEPT DLE has required attention to all of the aforementioned components.

The software development process of the ADEPT DLE technologies has employed "reductionist" (Chen, Qiyang, Sharma and Vinai, 2002) or "abstractionist" (Martin, 1996) approaches to system design, which encourage decomposition of complex systems into small, manageable components, and the design of each component for "ideal world" environments. Such design approaches risk failure if they do not also attend to human user and real world factors (Ewusi-Mensah, 2003). Also notable in the ADEPT project are the differences between the functional roles and related world-views of designers and users (McConnell, 2003), and the resulting management challenges (Constantine, 2001).

The introduction of technology to the classroom has a long and turbulent history of grand promises and even grander shortcomings. From Thomas Edison's enthusiasm for film's use in education with his not-so-prophetic declaration that "Books will soon be obsolete in the schools" in 1913 (Cuban, 1986), to the present efforts to integrate the Internet into the classroom, the struggle technology's advocates have faced are well documented (Apple, 1998; Burbules, 2000; Cordes, 2000; Cuban, 1986).

While each academic setting has its own unique sets of obstacles to overcome in attempting to introduce technology, several scholars interested in technology's use in higher education have used Everett Rogers' Diffusion of Innovations theories (1995) as a basis for modeling the adoption process (Carr, 1999; Donovan, 1999; Garofoli and Woodell, 2003; Geoghegan, 1994; Hagner and Schneebeck, 2001). Rogers' Diffusion of Innovations theories are by far the most commonly applied model for the adoption process to explain the success or failure of technologies introduced in the past two decades. With over 70 published articles in information technology journals between 1984 and 1994 citing Rogers' theories (Prescott and Conger, 1995) some have accused DOI theory of being too general and too widely applied (Larsen, 1995). Others have claimed that the application of DOI theory is inappropriate in situations in which; the adopters' decisions are heavily influenced by authority (Fichman, 1992) or political 
positioning within a given industry, the innovation is exceptionally complex and networked, or the rate of adoption for a given innovation spikes drastically (Lyytinen and Damsgaard, 2001).

Despite these criticisms, Rogers' DOI theories are especially useful in modeling the adoption decision made by instructors in higher education. In Fichman's review of empirical research on information technology diffusion, he identified characteristics of adoption environments that were most likely to follow Rogers' DOI models (Fichman, 1992). The category of adoption most likely to be explained accurately by Rogers' theory was characterized by having the responsibility of the adoption decision left to an individual and the knowledge burden imposed by the innovation to be relatively low. Low knowledge burden is defined as any technology for which the basic functionalities could be learned in a few hours' time. The situation under study lends itself well to Fichman's categorization due to the relative professional autonomy of instructors in higher education, the ability of instructors to learn to create lectures in less than a few hours' time, and the technological competence required of geography professors.

Rogers' defines adoption as, "a decision to make full use of an innovation as the best course of action available." (p.21). The decisions to use the ADEPT DLE in classroom implementations by each participating instructor to date have been decisions to adopt the innovation for experimental use in teaching. In using Rogers' adoption models to analyze the ADEPT DLE's transition from experimental prototype to deployable system, a distinction is made between the decision of instructors to participate in highly supported experimental classroom deployments and the project's current goal of promoting adoption of the DLE for independent use by instructors. This distinction is further warranted by the changes in functionalities and volatility of the system prior to its current "deployable" form, and more importantly, by the current lack of unlimited support for lecture building previously provided to instructors by ADEPT staff.

Applying diffusion of innovation theory to the adoption of learning technologies in the college teaching environment, professors (the audience targeted by ADEPT) can be parceled into five categories of participants: 1) innovators who tend to take pride in being one of the first to experiment with a new technology; 2) early adopters who are usually also technologically samy and see the potential to solve a problem with the 
technology; 3) the early majority who would be considered the first half of the mainstream adoption; 4) late majority who tend to take more of a wait and see approach; 5) laggards that may be critical of the technology and resist its adoption. The distribution of the types of adopters is normally distributed.

According to Rogers' perceived attributes theory, the decision to adopt an innovation is based on five perceived attributes of the innovation itself. The characteristics upon which the decision to adopt is made are: 1) trialability, which is the extent to which it can be experimented with; 2) observability, which measures whether the results of using the innovation can be seen; 3 ) relative advantage, over the current practice; 4) complexity, which determines how difficult the innovation will be to learn; 5) compatibility, or how well it fits into the circumstances into which it is being introduced (Rogers, 1995).

\section{Methods}

The decision to adopt a technology is often a complex one, with several factors playing a role. The application of Rogers' DOI framework to an analysis of both the characteristics of the innovation (the ADEPT DLE), as well as the potential audience of adopters (undergraduate geography instructors), offers an explanation for why the decision to adopt is or is not made. More specifically, viewing the adoption decision of instructors through the lens of Rogers' framework provides insights as to which of the several factors of adoption are most important, as well as which potential adopters to target first and with what incentives.

The analysis provided in this review is based on the accumulated ethnographic, qualitative data collected on the design and implementation processes as they proceeded throughout the 2002-2003 and into the 2003 - 2004 academic year, as well as quantitative data collected from student course evaluations for the 2002 - 2003 academic year. This data was collected a variety of settings, including development and design team meetings, interviews with individual developers, pre and post implementation interviews with professors, student course evaluations, and scientific 
reasoning sets completed by students. Details of the collection of this data can be found in Borgman, Leazer et al., 2001; Borgman, Smart et al., 2004; Champeny, Borgman et al., 2004; Gazan, Leazer et al., 2003; Leazer, Gilliland-Swetland et al., 2000.

\section{Results}

Instructors who have participated in ADEPT prototype deployment thus far have made conscious adoption decisions in choosing to implement the ADEPT DLE in their classrooms. In doing so, they have weighed the perceived cost of adoption versus the perceived benefits of adopting. Geography is a technology-intensive field, particularly in areas covered by these instructors, which include climatology and geomorphology. Even so, few instructors normally employ computer-based instructional technology in their teaching. When asked their reasons, they said that too much advance planning was required for computer-based instruction and that too much assistance would be required to install and support the equipment (Borgman, Gilliland-Swetland et al., 2000). They were interested in experimenting with new instructional methods, however, and were willing to participate in ADEPT because the equipment, technical assistance, and graduate assistance support for developing lecture materials were all provided. Several of the instructors commented that they would prefer, at least initially, to have "canned" materials, rather than live digital libraries or online connections in the classroom. Two faculty members commented that they did not wish to present a technology-based lecture in front of 100 or more students "without a safety net." In order to gain their participation, the ADEPT team devoted substantial resources to lowering the cost of adoption. This deliberate investment of resources has afforded us the opportunity to gain valuable design and evaluative insights. Additionally, it has offered the design team the technical flexibility they have needed, rather than spending time troubleshooting and bug fixing.

While the design decisions made thus far have been beneficial throughout the project's experimental stage for realizing research-related goals, issues of practicality and adoption now take priority as general system use is considered. For example, in our first 
full-course classroom implementation the instructor requested that approximately 1,000 concepts be created for the 10-week course. At an estimated one-hour of labor per concept, the approximately 1,000 concepts would have required the equivalent of 25 weeks of full-time labor (or at least two and half quarters of fulltime course preparation) (Champeny, Borgman et al., 2004). In addition, the previous method of lecture creation will become problematic. Most of the images used were copied from textbooks and digitized or found through Web searches. While this method of image gathering mirrors methods of many instructors seeking images for their lectures (Borgman, Smart et al., 2004), it has hindered bi-directional integration with the Alexandria Digital Library, preventing the ability to store teacher objects with copyrighted material in the library for public use.

In order to frame the transition from experimental prototype to deployable system, Rogers' Perceived Attributes and Classes of Adopters Theories are applied.

\section{Rogers' Perceived Attributes Theory Applied}

\section{Trialability}

The first perceived characteristic Rogers provides is trialability. He suggests that the trialability of an innovation, as perceived by the members of a social system, is positively related to its rate of adoption. Further, he finds that relatively early adopters place more weight on being able to experiment with an innovation that later adopters do (Rogers, 1995). In each implementation thus far, instructors have been offered as much training and as many opportunities to experiment as they would like before the classroom implementation. Additionally, ADEPT team members have been available for regular consultation throughout the term of the deployment. The participation of the ADEPT team, in effect, has guaranteed that the technology could be experimented with by the instructors with the added benefit of a safety net in case their experimentation led to the discovery of any system errors or unanswered questions they might have. 
Any effort by the ADEPT team to recruit instructors has featured a demonstration of the DLE. These demonstrations have been designed to highlight the latest functionalities of the system as it has progressed. These presentations have been followed by a question and answer period, as well as an offer to provide further access to the system with the support of an ADEPT team member. By doing so, the ADEPT team has made the features and functionalities of the system clear to the potential adopters, thereby increasing the chance of adoption.

Relative Advantage

Relative advantage is described by Rogers as the degree to which an innovation is perceived as better than the idea it supercedes (Rogers, 1995). For the majority of adopting instructors, a considerable advantage has come from the shift in lecture format. For the instructors recruited for the ADEPT project that used the chalkboard, transparencies, or a combination of the two to present lectures, the advantage of presenting digital high-resolution color images over using projected transparencies was cited as a reason for participation (Borgman, Gilliland-Swetland et al., 2000).

Professors that already used a computer to create and project lectures with either HTML, Microsoft PowerPoint, Microsoft Word or some other application, still needed their lectures created in the DLE. While having their lectures converted to digital form was not an incentive, using the DLE meant that lecture topics could be converted to concepts, the relationships between which were represented graphically. Further, these professors were offered the support of graduate assistants and often the ADEPT design team for finding more suitable materials for their lectures. A staff devoted to finding better lecture materials and creating lectures with them is obviously an attractive proposition for busy instructors.

Without graduate assistants or ADEPT team members devoted to lecture creation, instructors considering adoption are faced with the added work of transcribing their existing materials into the Lecture Composer. The Lecture Composer features many of 
the same basic word processing functionalities as Microsoft Word, and text can be "pasted" into the interface, making the task less daunting for those with existing lectures in digital format. However, in its current state, the import of images into the system requires that the user be familiar with using a file transfer protocol (FIP) client to send images to the remote server. A less complex import functionality promised by the design team must be provided in order to eliminate unnecessary effort from the use of the application. For those with lecture materials on either transparency or paper, the process won't be as painless. However, the advantage of moving from their current format to a more portable and more easily edited digital format may be enough to compensate for the extra effort involved in converting to the DLE.

\section{Complexity}

Negatively related to the rate of an innovation's adoption is the degree to which it is perceived as relatively difficult to understand and to use (Rogers, 1995). In order to assure instructor participation, the ADEPT team has handled the technical creation of most lectures. As a result, instructors were protected from the inherent complexity and volatility of the experimental ADEPT DLE. In recognition of the need to offer a more stable system to their users, the design team announced a shift in focus from experimentation to stabilization in the fall 2003 quarterly meeting. They soon after designated one full time developer to create a single interface to simplify the use of the system which previously presented as a series of sub-applications, each one performing its own specific task. In addition they purchased a commercial bug-tracking software package that allowed users and fellow developers to enter problems and assign them to the appropriate developers.

Despite significant improvements in the system since then, a lack of technical documentation, scarce attention to defects, and incomplete functionalities have plagued the system throughout its classroom deployments. The importance of offering a stable system, complete with readily available documentation, cannot be overstated. Until this is complete, the potential audience of adopters is limited to the fault-tolerant innovators and early adopters, which represent a very small proportion of the potential audience of adopters. 
Compatibility

Compatibility is the degree to which an innovation is perceived as consistent with the existing values, past experiences, and needs of potential adopters (Rogers, 1995). The ADEPT project's values can be assumed to be consistent with the existing values of instructors, who also have the goal of teaching students as effectively as possible. The specifics of which methods are best for achieving this goal has been a subject of concern for the ADEPT teams from the outset.

In its earliest implementation, the ADEPT design team molded the technology to match the pedagogical beliefs of our first participating instructor. Such an approach guaranteed a match for this particular instructor, but at the cost of pushing a conceptbased approach on subsequent participants. In a more recent implementation, an instructor's request for scaleable, layered images with custom labels has led to resources devoted to finding and creating such custom images. Such approaches have assured instructors using the ADEPT system that it is compatible with their current values. The design team's willingness to accommodate the pedagogical preferences of participating instructors has been a selling point for some of the adopting instructors. While such efforts have been valuable for the hypothesis driven design of the experimental prototype, they are not sustainable in wide-scale deployment nor have they been implemented with consideration for compatibility with existing practice.

The design team's focus on stabilizing the Lecture Composer has been a step in the direction of wide-scale implementation. It is the component of the system most similar to existing lecture creation and presentation packages currently available, and is therefore likely to be the least foreign component for instructors. Fortunately, it is also the component most used by participating instructors.

\section{Rogers' Classes of Adopters Applied}

The most obvious targets for adoption of the ADEPT DLE are instructors of 
undergraduate geography. However, they are not the sole intended users of the system. The ADEPT DLE was designed to be accessible by students, allowing them to revisit topics outside of their scheduled class time. Additionally, teaching assistants were instrumental in the creation of lectures during our experimental deployments, and would most likely be enlisted to participate in this capacity by any adopting instructor in the future. Intentional consideration of the utility of the system for students, and considerable time invested in training teaching assistants to create lectures, both increase the likelihood of adoption by adding to the instructor's perceived relative advantage of the system. More specifically, if an instructor is confident that graduate research assistants are comfortable using the system or that value is added to the students through some functionality of the system, then the instructor has additional reasons to adopt. However, efforts to diffuse the ADEPT DLE must consider instructors the primary audience. It is, after all, the decision of the instructor to adopt or reject a classroom learning technology that dictates whether their teaching assistants and students access the system.

Having identified instructors as the primary target for adoption, Rogers' framework dictates that the population of all instructors of geography falls into one of five classes of adopters, based on how soon they adopt an innovation after its introduction. These classes are the innovators, early adopters, early majority, late majority and laggards. The distribution of these categories, according to DOI, will be normally shaped, with innovators and laggards making up the tails of the distribution and the majority of the adopters falling into the categories of either early majority or late majority. By understanding the categories into which specific undergraduate geography professors belong, one can gauge how difficult it may be to persuade a given instructor to adopt the ADEPT DLE. Furthermore, by recognizing the typical motives that drive certain categories of adopters to adopt, the choices of which instructors to target and with what incentives can be made strategically.

Thus far, most adopters of the experimental DLE can be classified as either innovators or early adopters. Adopters that fall in these categories are familiar with the volatility of experimental systems. As such, their characteristics as potential adopters indicate that they are far more tolerant of system instability and/ or gaps in functionality. This allowed the design team to delay troubleshooting while developing a more flexible but 
unstable prototype for this class of adopters. Even so, these instructors were "protected" from most technical issues by the ADEPT team taking on the responsibility of all aspects of lecture creation in most cases. As the focus of the project transitions from experimentation to deployment, the amount of resources available to guide instructors through the creation of lectures will be scaled back significantly. The obstacle to adoption that the retraction of support will create will be significant for innovators and early adopters, but even more so for the early majority, late majority, and laggards. A transition from targeting the innovators and early adopters to recruiting the early majority should feature a stable system, including the previously mentioned readily available demo and complete technical documentation, but will also benefit from learning of the positive experiences of the previous adopters.

\section{Discussion}

Considerations of the results of the application of diffusion of innovation theory can guide future design and deployment decisions. First, in order to assure instructors that the system can be easily experimented with, documentation must be developed and made readily available for anyone interested in accessing it. Additionally, news of available Web access to the application should be distributed among the target audience along with a trial username and password for all those interested in experimentation. The creation of a multimedia demonstration would also contribute to the perceived observability of the technology. It would provide instructors a first look at the system's capability without requiring that they attend a scheduled demonstration. This presentation should be accessible from the same Web page that extends the opportunity for anonymous users to experiment with the application.

To increase the observability for future potential adopters, demonstrations should continue on a quarterly basis. These demonstrations involve minimal effort on the part of the ADEPT support staff and present an opportunity to showcase advances in the system to professors that participated in prior demonstrations. Additionally, question and answer sessions after such demonstrations offer the design team the insights of potential adopters that can bring fresh perspectives to the team. Although the system 
has been in classroom use since 2000 , the forms it has taken on have changed dramatically as its previous designs were used mostly to test the validity of several possible approaches. Efforts to stabilize the system are relatively recent and as a result, it can be expected that classroom implementations will continue to uncover minor defects, as well as offer design suggestions for streamlining processes. It will therefore be advantageous to continue to seek out innovators and early adopters to assist the ADEPT team in the discovery of such issues. According to Rogers' categorizations, these audiences will be the most interested in participating while the system is still considered new and innovative. Efforts to attract such participants should emphasize the value that will be added by participating instructors' abilities to trouble shoot and make suggestions for improvement.

In order to meet these goals, the design team has designated a fulltime developer to the integration of the DLE's components. They have also employed a bug-tracking software tool, which allows multiple users to report bugs and developers and managers to assign the solving of these problems through the tool. Additionally, they have set delivery "deadlines" for certain improvement to be completed by.

The implementation of such measures is a critical step in the right direction. However, what may prove more difficult is an overall change in development philosophy that's been employed for nearly five years. The opportunity to participate in experimental software design can be perceived by some software developers to be a rather attractive assignment. It can be an opportunity for developers to apply their skills to unsolved problem ins ways never before attempted. The ADEPT project encouraged this sort of freethinking, and supported its developers use of whatever technologies they deemed fit. Bug fixing and troubleshooting can be considered a far more mundane task. There is a natural tension between the teams of people that create software and the people assigned to pointing out its flaws. This philosophical transition will be critical in the project's transition.

The ADEPT team's educational goal has always been a shift in pedagogy and previous implementations of the DLE have experimented with such alternative approaches. However, the speed at which a pedagogical change is achieved should be rethought in order to guarantee compatibility with the current practices of a larger audience of 
instructors to promote adoption. To accomplish true pedagogical change, system design must be an ongoing process, driven by power users that fully understand the system's present offerings and can drive the designers toward the types of changes that make the most sense from their perspective.

In order to increase the compatibility of the DLE for instructors that are familiar with other presentation or desktop publishing packages, the Lecture Composer should be the component for which the most training time is devoted. Instructors can work with functionalities that can be considered less compatible to existing practice, such as drawing relational hierarchies between concepts, after they have established a level of comfort with the application's basic lecture building/ lecture presentation features.

Finally, an original promise of the ADEPT DLE was its integration with the Alexandria Digital Library. Unfortunately, technical and copyright difficulties have prevented a true integration between ADEPTs DLE and the digital library. The technical challenges have stemmed from a variety of sources, including the incompatibility of the various technical approaches taken, and development efforts aimed elsewhere. Copyright difficulties were derived from the inclusion of images into lectures without having first gained legal permissions. Delivering this functionality would offer the opportunity for professors to search and obtain high quality, contextually appropriate geographical materials. In addition, teaching objects, composed of images and lectures, could be shared among professors. This could lead to the inclusion of more primary source data in classroom learning, which was one of the original pedagogical goals of the project. Such a capability would increase the relative advantage of the system, hopefully speeding its rate of adoption.

\section{Conclusion}

In order for the ADEPT DLE to become a viable learning tool available to undergraduate geography professors, the ADEPT design team is attempting a reprioritization of its resources. Rogers' models for the diffusion of innovation can offer the guidelines for helping to refocus the efforts of the design team toward the widespread diffusion of their innovation. The delivery of a stable system must be the first priority of any 
development effort. Success in this regard would greatly lower the perception of complexity and lend more credibility to any promise of independent experimentation offered to professors, thereby improving the perceived level of trialability. Recruitment of instructors with the characteristics of innovators and early adopters in the immediate future will contribute to this goal by their acting as trouble-shooters, offering suggestions to increase the usability of the system, and generating positive word of mouth before the system is deployed to adopters falling into the category of early majority.

a ADEPT is funded by National Science Foundation grant no. IIS-9817432, Terence R. Smith, University of California, Santa Barbara, Principal Investigator.

\section{References}

Apple, M. (1998). Teaching and Technology: The hidden effects of computers on teaching and students. In M. A. L. Beyer, The curriculum: Problems, politics, and possibilities (pp. 314 - 336). New York: State University of New York Press.

Borgman, C. L., Gilliland-Swetland, A. J., Leazer, G. H., Mayer, R., Gwynn, D., Gazan, R. and Mautone, P. (2000). Evaluating Digital Libraries for Teaching and Learning in Undergraduate Education: A case study of the Alexandria Digital Earth Prototype (ADEPT). Library Trends 49(2), 228-250.

Borgman, C. L., Leazer, G. H., Gilliland-Swetland, A. J. and Gazan, R. (2001). P. Constantopoulos and I. T. Sølvberg. Iterative design and evaluation of a geographic digital library. In Research and Advanced Technology for Digital Libraries, 5th European Conference (ECDL 2001), Darmstadt, Germany: Springer.

Borgman, C. L., Smart, L. J., Millwood, K. A., Finley, J. R., Champeny, L., GillilandSwetland, A. J. and Leazer, G. L. (2004). Comparing Faculty Information Seeking in Teaching and Research: Implications for the Design of Digital Libraries. Journal of the American Society for Information Science \& Technology, 56(6): 636-657.

Burbules, N., Callister (2000). Watch IT. Boulder, CO: Westview Press. 
Carr, H. V. (1999). Technology Adoption and Diffusion, United States Air Force War College. Retrieved February 27, 2004, from

http://www.au.af.mil/au/awc/awcgate/innovation/adoptiondiffusion.htm

Champeny, L., Borgman, C. L., Leazer, G. H., Gilliland-Swetland, A. J., Millwood, K. A., D'Avolio, L., et al. (2004). Developing a Digital Learning Environment: an evaluation of design and implementation processes. ACM/IEEE-CS Joint Conference on Digital Libraries (JCDL 2004), Tucson, AZ: ACM Press.

Chen, Qiyang, Sharma and Vinai (2002). Human factors in interface design: an analytical survey and perspective. In E. J. Szewczak and C. R. Snodgrass. Human Factors in Information Systems (pp. 45-54). Hershey, PA: IRM Press.

Constantine, L. (2001). Beyond Chaos: the Expert Edge in Managing Software Development. Boston: Addison Wesley.

Cordes, M. (2000). Fool's gold: A critical look at computers in childhood.

Cuban, L. (1986). Teachers and machines. Cambridge, MA: MIT Press.

Dewald, N. H. and Clair, G. S. S., Eds. (1997). Libraries and other Academic Support Services for Distance Learning. Greenwich, CT: JAI Press.

Donovan, M. (1999). Rethinking Faculty Support. The Technology Source. Retrieved February 27, 2004, from http://ts.mivu.org/default.asp?show=article\&id=612

Ewusi-Mensah, K. (2003). Software Development Failures: Anatomy of Abandoned Projects. Cambridge, MA, MIT Press.

Fichman, R. G. (1992). Information Technology Diffusion: A Review of Empirical Research.

Garofoli, E. and Woodell, J. (2003). Faculty Develoment and the Diffusion of Innovations. Available at http://www.syllabus.com/article.asp?id=7093

Gazan, R., Leazer, G. H., Borgman, C. L., Gilliland-Swetland, A. J., Smart, L., Ancona, D. and al., e. (2003). Use Scenarios in the Development of the Alexandria Digital Earth Prototype. Humanizing information technology: from ideas to bits and back. Proceedings of the 66th ASIST Annual Meeting, Longbeach, CA. 
Geoghegan, W. H. (1994). Whatever Happened to Instructional Technology. 22nd Annual Conference of the International Business Schools Computing Association, Baltimore, MD.

Gilliland-Swetland, A. J. and Leazer, G. H. (2001). Iscapes: digital learning environments for the promotion of scientific thinking by undergraduates in geography. First ACM/IEEE-CS Joint Conference on Digital Libraries, Roanoke, VA.

Hagner, P. and Schneebeck, C. (2001). Engaging the Faculty. Educause Leadership Strategies, Technology-Enhanced Teaching and Learning: Leading and Supporting the Transformation on Your Campus, 5.

Hill, L. and Freeston, M. (2003). Introduction to Georeferencing in Digital Libraries, Tutorial. Presented at the Joint Conference on Digital Libraries, Houston, TX.

Hill, L. L., Carver, L., Larsgaard, M., Dolin, R., Smith, T. R., Frew, J. and Rae, M. A. (2000). Alexandria Digital Library: User evaluation studies and system design. Journal of the American Society for Information Science. 51(3): 246-259.

Janee, G. (2003). Issues in Georeferenced/Geospatial Digital Libraries: Position Paper.

Janee, G. and Frew, J. (2002). The ADEPT Digital Library Architecture. ACM/IEEECS Joint Conference on Digital Libraries (JCDL), Portland, OR: ACM Press.

Larsen, T. J. (1995). M. A. Ardis and B. L. Marcolin. The Phenomenon of Diffusion, Red Herrings and Future Promise. IFIP TC8 WG8.6 Fourth Working Conference on Diffusing Software Product and Process Innovations, Banff, Canada: Kluwer Academic Publishers.

Leazer, G. H., Gilliland-Swetland, A. J., Borgman, C. L. and Mayer, R. (2000). Classroom Evaluation of the Alexandria Digital Earth Prototype. ASIS 2000 Knowledge Innovations: celebrating our heritage, designing our future. Proceedings of the 63rd ASIS Annual Meeting, Chicago, IL.

Lyytinen, K. and Damsgaard, J. (2001). M. A. Ardis and B. L. Marcolin. What's Wrong with the Diffusion of Innovation Theory? IFIP TC8 WG8.6 Fourth Working 
Conference on Diffusing Software Product and Process Innovations, Banff, Canada: Kluwer Academic Publishers.

Martin, F. G. (1996). Ideal and real systems: a study of notions of control in undergraduates who design robots. In Y. Kafai and M. Resnik. Constructionism in Practice: Designing, Thinking, and Learning in a Digital World (pp. 297 - 322).

Mahwah, NJ: Lawrence Earlbaum Associates.

Mayer, R. E., Mautone, P. and Prothero, W. (2002). Pictorial aids for learning by doing in a multimedia geology simulation game. Journal of Educational Psychology 91(4): 171 - 185.

McConnell, S. (2003). Professional Software Development: Shorter Schedules, Better Projects, Superior Products, Enhanced Careers. Boston: Addison Wesley.

Modell, H. I. and Michael, J. A., Eds. (1993). Promoting Active Learning in the Life Science Classroom. New York: New York Academy of Sciences.

Owen, J. M., Calnin, G. T. and Lambert, F. C. (2002). Evaluation of information technology (Chapter 6). In J. W. Altschuld and D. D. Kumar. Evaluation of Science and Technology in Education at the Dawn of New Millenium (pp. 133-164). New York: Kluwer Academic/Plenum Publishers.

Prescott, M. B. and Conger, S. A. (1995). Information Technology Innovations: A Classification by IT Locus of Impact and Research Approach. Data Base Advances $26(2,3)$ pp. $20-41$.

Rogers, E. M. (1995). Diffusion of Innovations. New York: The Free Press.

Smith, T. and Zeng, M. (2002). ADEPT Knowledge Organization Team. Structured models of scientific concepts as a basis for organizing, accessing and using learning materials. Joint Conference on Digital Libraries, Portland, Oregon: ACM Press. 